\title{
The Institute of Bioorganic Chemistry is 50-Years Old
}

DOI: $10.1134 / \mathrm{S} 1068162009060016$

The next two issues of the journal Bioorganicheskaya Khimia (Russian Journal of Bioorganic Chemistry) will be essentially compiled of publications of originated at the Shemyakin-Ovchinnikov Institute of Bioorganic Chemistry. In this way, the editorial board decided to celebrate the 50th anniversary of the Institute that has been sponsoring our journal. The subject area of the published manuscripts covers a wide spectrum of problems, from the isolation, structural identification, and synthesis of components of living matter to bioengineering, mechanisms of action of biomolecules, and the molecular basis of biological evolution. Reviews, self-reviews, as well as experimental papers and letters to the editor will be presented. The editorial board and editorial staff expect that both the spectrum of the discussed problems and the quality of manuscripts will allow our readers to properly evaluate the place and role of the Institute in domestic and international science and provide a genuine insight into the outstanding scientific potential of this prominent scientific unit.

Academician of the Russian Academy of Sciences V.T. Ivanov, Editor-in-Chief 